\title{
Article \\ The Impact of 3-(trihydroxysilyl)-1-propanesulfonic Acid Treatment on the State of Vanadium Incorporated on SBA-15 Matrix
}

\author{
Ardian Nurwita, Piotr Decyk, Maria Ziolek (D) and Maciej Trejda *(D) \\ Department of Heterogeneous Catalysis, Faculty of Chemistry, Adam Mickiewicz University, Poznań, \\ Uniwersytetu Poznańskiego 8, 61-614 Poznań, Poland; ardnur@st.amu.edu.pl (A.N.); piotrd@amu.edu.pl (P.D.); \\ ziolek@amu.edu.pl (M.Z.) \\ * Correspondence: tmaciej@amu.edu.pl; Tel.: +48-618291805
}

check for updates

Citation: Nurwita, A.; Decyk, P.; Ziolek, M.; Trejda, M. The Impact of 3-(trihydroxysilyl)-1-propanesulfonic Acid Treatment on the State of

Vanadium Incorporated on SBA-15 Matrix. Catalysts 2021, 11 397. https://doi.org/10.3390/ catal11030397

Academic Editors: Maria

Victoria Martínez Huerta and María Olga Guerrero-Pérez

Received: 26 February 2021

Accepted: 18 March 2021

Published: 21 March 2021

Publisher's Note: MDPI stays neutral with regard to jurisdictional claims in published maps and institutional affiliations.

Copyright: (c) 2021 by the authors. Licensee MDPI, Basel, Switzerland. This article is an open access article distributed under the terms and conditions of the Creative Commons Attribution (CC BY) license (https:// creativecommons.org/licenses/by/ $4.0 /)$.

\begin{abstract}
Bifunctional catalysts-e.g., those with acidic and redox sites-are of particular importance, especially in the cascade processes, including the one-pot transformation of glycerol to acrylic acid. In this study, we explore one aspect of the preparation of a vanadium-containing catalyst, which can be further modified with 3-(trihydroxysilyl)-1-propanesulfonic acid (TPS). The state of vanadium species loaded on mesoporous ordered silica of SBA-15 type was investigated before and after treatment with TPS, which can also be applied for the generation of acidic centers. Two vanadium sources, i.e., ammonium metavanadate and vanadium(IV) oxide sulfate, were applied to generate redox sites on SBA-15. The structure of materials obtained was analyzed using $\mathrm{N}_{2}$ adsorption/desorption and XRD measurements. For the estimation of the amount of vanadium and characterization of its state, the following techniques were applied: ICP, UV-Vis, XPS, ESR and FTIR combined with pyridine adsorption. The treatment of vanadium containing SBA-15 with TPS was found to lead to the oxidation of $\mathrm{V}^{4+}$ to $\mathrm{V}^{5+}$ and the partial removal of vanadium species, leading to a decrease in the number of penta-coordinated vanadium species. These features should be taken into account in the design of bifunctional catalysts with vanadium-active centers and $\mathrm{SO}_{3} \mathrm{H}$ acidic sites coming from TPS.
\end{abstract}

Keywords: vanadium; SBA-15; impregnation; TPS

\section{Introduction}

Vanadium-based catalysts have been successfully applied for a wide range of reactions which require the presence of redox sites, including, for instance, the oxidative dehydrogenation of alkanes to alkenes [1,2], oxidation of methanol to formaldehyde [3-5] or ammoxidation processes [6,7]. Many factors influence the activity of vanadium-containing catalysts, e.g., the type of vanadium source used for catalyst preparation and metal oxide dispersion on the support, metal oxidation state and reducibility or the kind of support. Promising supports for different active sites are ordered mesoporous silicas, e.g., MCM-41, SBA-15 or KIT-6, due to large surface areas and uniform systems of pores whose diameter can be controlled by the application of different templates. These features permit us to obtain good dispersion of active species.

Mesoporous silicas have also been applied as supports for vanadium species, e.g., MCM-41 [1], SBA-15 [8] or KIT-6 [9]. In addition to the dispersion of vanadium species, the final oxidation state of vanadium, incorporated in the one-pot synthesis procedure of SBA15 and KIT materials, has been shown to depend on the type of mesoporous support [9]. The modification with vanadium resulted in the appearance of mainly $\mathrm{V}^{5+}$ species in the KIT-6 sample, whereas a mixture of $\mathrm{V}^{4+}(31 \%)$ and $\mathrm{V}^{5+}(69 \%)$ on the SBA-15 support.

Recently, much effort has been focused on catalytic cascade processes that can reduce the number of operations and, finally, the cost of production of desired bulk or fine chemicals. This strategy mostly requires the application of bifunctional catalysts. An 
interesting example is the transformation of glycerol to acrylic acid [10,11]. In this process, glycerol is first dehydrated to acrolein on acidic sites, followed by oxidation to acrylic acid on redox sites. For this purpose, vanadium-containing catalysts have also been applied [12]. It is known that mesoporous silica is an attractive support for Brønsted acid sites. The sites of this type can be generated by the immobilization of organosilane species, which is mainly realized by the incorporation of (3-mercaptopropyl)trimethoxysilane (MPTMS) by grafting or co-condensation during the synthesis of ordered mesoporous silica. The formation of Brønsted acid sites requires the oxidation of SH species in MPTMS, which is performed most commonly by hydrogen peroxide. Unfortunately, this method has some drawbacks; for instance, an excess of $\mathrm{H}_{2} \mathrm{O}_{2}$ must be applied (much more than the stoichiometric amount), or the oxidation process can lead to the partial removal of MPTMS previously grafted on the silica surface [13].

Organosilane species, such as MPTMS immobilized on different silicas, not only allow the generation of acidity on the surface of the support. These species can also interact with the support or with the other modifiers incorporated into the catalyst. This is important, because such an interaction can change the properties of the modifier. In our previous work, we observed the positive impact of niobium present on SBA-15 and mesostructured cellular foam (MCF) on the efficiency of thiol species oxidation into sulfonic species [14]. Moreover, the interaction of niobium species with an organosilane modifier resulted in the better thermal stability of oxidized MPTMS. It was also found that the interaction observed did not depend on the kind of silica structure. Thus, it seems to be important to consider and investigate a possible interaction of other organosilane species with the metalosilicate supports.

Recently, we successfully applied 3-(trihydroxysilyl)-1-propanesulfonic acid (TPS) instead of MPTMS for the generation of Brønsted acid sites on an SBA-15 support [15]. The TPS modifier already has $\mathrm{SO}_{3} \mathrm{H}$ groupings; thus, the oxidation of $\mathrm{SH}$ species is not necessary. However, there are no literature data concerning the interaction of dispersed vanadium species supported on mesoporous silica with TPS species, which can further influence the catalytic behavior of the final material. Therefore, the objective of this work was to investigate the vanadium state in the mesoporous silica of SBA-15 type, determined by the addition of two different metal precursors, followed by the interaction with TPS species. For this reason, the impregnation-based procedure of TPS, instead of the grafting method, was applied to reduce the possible incorporation of TPS species on the silica support. The objective was to answer the question concerning the influence of TPS used for the formation of bifunctional redox (vanadium)-acid (TPS-sulfonic groups) catalysts on the redox and acidic characteristics of vanadium species. Thus, the modification conditions were chosen in a manner that would enable the final removal of all TPS, allowing the exclusive characterization of vanadium species.

\section{Results and Discussion}

Two sources of vanadium, i.e., ammonium metavanadate $\left(\mathrm{V}_{\mathrm{M}}\right.$ in catalyst symbol) and vanadium(IV) oxide sulfate $\left(\mathrm{V}_{\mathrm{S}}\right.$ in catalyst symbol), were applied for modification of mesoporous silica of SBA-15 type. These samples were also treated with 3-(trihydroxysilyl)1-propanesulfonic acid (TPS). To avoid the formation of vanadium oligomers, a relatively small loading of the metal was applied, i.e., $<2 \% \mathrm{wt}$. The final concentration of vanadium according to ICP analysis was 1.7 and $1.0 \%$ wt. for $\mathrm{V}_{\mathrm{M}} / \mathrm{SBA}-15$ and $\mathrm{V}_{\mathrm{S}} / \mathrm{SBA}-15$, respectively (Table 1). The samples treated with TPS showed a slightly lower concentration of vanadium, which indicates a partial vanadium removal during the modification.

The SBA-15 support was prepared by hydrothermal synthesis. The obtained sample showed a structure typical of the ordered mesoporous materials based on silica. Figure 1A presents the XRD pattern of the support. An intense (100) peak located at 2 theta ca. $1.2^{\circ}$ was observed. Its presence is typical of hexagonally ordered mesoporous solids and is related to the reflections of the hexagonal plain group p $6 \mathrm{~mm}$. The two characteristic peaks, i.e., (110) and (200), were barely discernible. Their presence can be connected with the 
ordering of channels; thus, one should expect that the arrangement of the channels is not well developed. The modification of the SBA-15 support with vanadium did not have an impact on the material structure, as can be deduced from the XRD patterns. However, a decrease in the intensity of the (100) peak was observed after modification with vanadium species, mainly for the $\mathrm{V}_{\mathrm{S}}$ /SBA-15 sample. In the literature, this feature was assigned to the location of different modifiers inside the material pores. Additionally, for $V_{M} / S B A-15$, a small shift of the (100) peak to lower values of 2 theta was observed. This points to the increase in cell parameter of the sample obtained after modification with ammonium metavanadate. This can be caused by at least partial incorporation of vanadium species into the walls of the material. A similar effect has been described in the literature for niobium species on SBA-15 [13]. As shown in Figure 1B, the incorporation of vanadium species did not allow the formation of crystalline vanadium $(\mathrm{V})$ oxide large enough for XRD detection, as the characteristic XRD peaks were not present for $V_{S}$ /SBA-15, and they were barely seen for $V_{M} / S B A-15$. This observation points to a good isolation of vanadium species, which was also confirmed by the UV-Vis and ESR measurements.

Table 1. Texture/structure characterization and vanadium incorporation efficiency.

\begin{tabular}{|c|c|c|c|c|c|}
\hline Catalyst & $\begin{array}{c}\mathrm{S}_{\text {Total }} \\
\left(\mathrm{m}^{2} \mathrm{~g}^{-1}\right)\end{array}$ & $\begin{array}{c}\text { PSD }^{1} \\
(\mathrm{~nm})\end{array}$ & $\begin{array}{c}S_{\text {micro }} \\
\left(m^{2} g^{-1}\right)\end{array}$ & $\begin{array}{c}\mathrm{V}_{\text {Total }} \\
\left(\mathrm{cm}^{3} \mathrm{~g}^{-1}\right)\end{array}$ & $\begin{array}{c}V^{\text {V Content }}{ }^{2} \\
(w t \%)\end{array}$ \\
\hline SBA-15 & 753 & 5.5 & 0.12 & 0.57 & - \\
\hline $\mathrm{V}_{\mathrm{M}} / \mathrm{SBA}-15$ & 562 & 5.5 & 0.07 & 0.46 & 1.7 \\
\hline $\mathrm{TPS} / \mathrm{V}_{\mathrm{M}} / \mathrm{SBA}-15$ & 457 & 5.5 & 0.05 & 0.38 & 1.3 \\
\hline $\mathrm{V}_{\mathrm{S}} / \mathrm{SBA}-15$ & 687 & 5.5 & 0.10 & 0.53 & 1.0 \\
\hline TPS/V $/$ S SBA-15 & 561 & 5.5 & 0.07 & 0.47 & 0.7 \\
\hline
\end{tabular}

${ }^{1}$ Pore size distribution—calculated by DFT method; ${ }^{2}$ estimated by ICP method.
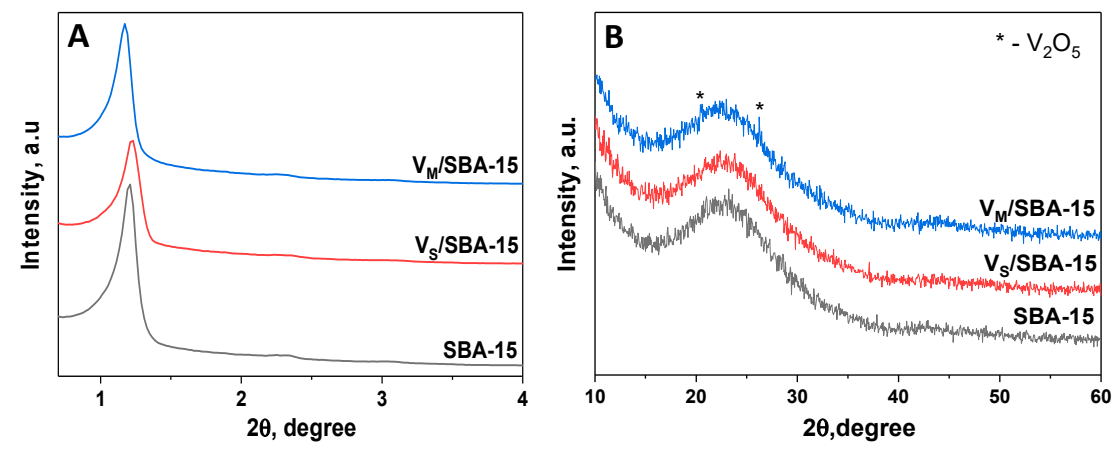

Figure 1. Small-angle (A) and wide-angle (B) XRD patterns of SBA-15 before and after modification with vanadium precursors.

Further detailed features of the materials' structure and textural properties were determined by low temperature $\mathrm{N}_{2}$ adsorption/desorption measurements. The obtained isotherms, as well as pore size distribution (PSD) calculated using the DFT method, are shown in Figure 2. A typical isotherm of type IVa according to the International Union of Pure and Applied Chemistry (IUPAC) classification [16] and characteristic of mesoporousordered materials was observed for SBA-15 support.

A characteristic feature of this type of isotherm is the presence of a saturation plateau at a high value of relative pressure $\mathrm{p} / \mathrm{p}_{0}$, and a hysteresis loop due to the condensation of $\mathrm{N}_{2}$ inside the pores of the material. The hysteresis loop is of type H1, which indicates that the pores of the SBA- 15 support are narrow and uniform. As indicated by the DFT results, most of the material pores are in the range between 5 and $7 \mathrm{~nm}$. The same type of isotherms and hysteresis loops were observed for the materials after modification with vanadium and interaction with TPS. The textural parameters of the materials obtained are presented in Table 1. The surface area of the support was relatively large and reached $753 \mathrm{~m}^{2} \mathrm{~g}^{-1}$, whereas the pore volume of this sample reached $0.57 \mathrm{~cm}^{3} \mathrm{~g}^{-1}$. Both parameters decreased 
after modification with vanadium; however, the change was more pronounced for the sample modified with ammonium metavanadate. After the interaction of vanadium species with TPS, a further decrease in the mentioned parameters was observed. Nevertheless, the surface area of the samples was still relatively large. In sum, all materials obtained within this study showed a typical structure of SBA-15 support with textural parameters characteristic of this mesoporous ordered silica.
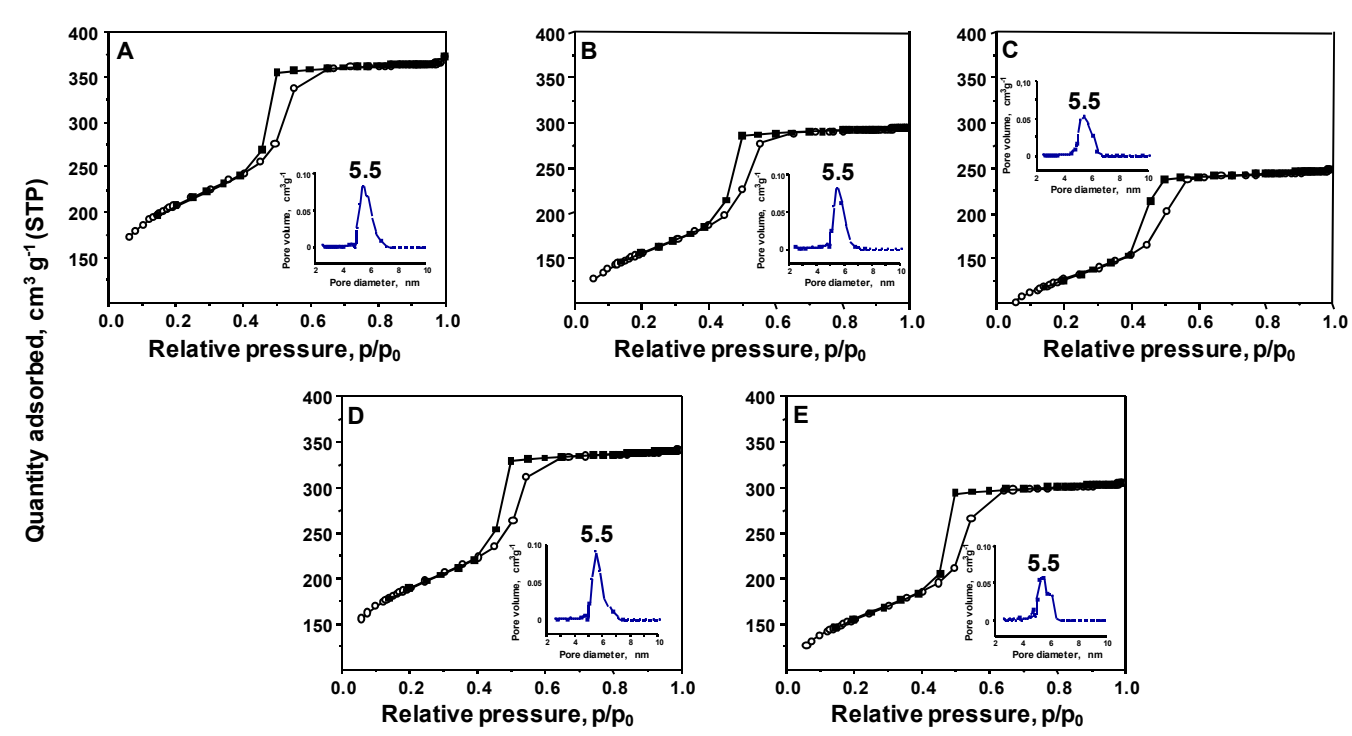

Figure 2. $\mathrm{N}_{2}$ adsorption/desorption isotherms and pore size distribution of materials obtained. (A) SBA-15, (B) $\mathrm{V}_{\mathrm{M}} / \mathrm{SBA}-15$, (C) TPS $/ \mathrm{V}_{\mathrm{M}} / \mathrm{SBA}-15$, (D) $\mathrm{V}_{\mathrm{S}} / \mathrm{SBA}-15$, (E) TPS $/ \mathrm{V}_{\mathrm{S}} / \mathrm{SBA}-15$

The coordination environment of vanadium species incorporated on the SBA-15 surface was investigated by UV-Vis analysis. Due to the sensitivity of vanadium species to moisture, the spectra were obtained for hydrated (white color) and dehydrated (yellow color) samples. The spectra of all samples are included in Figure S1, whereas the representative spectra of $\mathrm{V}_{\mathrm{M}}$ /SBA-15 are presented in Figure 3. The spectra of the hydrated sample showed four bands at 247, 317, 384 and $446 \mathrm{~nm}$. The first absorption band at $247 \mathrm{~nm}$ - which is a dominant one for the dehydrated sample-is assigned to low-energy charge transfer (CT) transition between oxygen and isolated $\mathrm{V}^{5+}$ cations [17-19]. The second band at ca. $317 \mathrm{~nm}$, according to the literature, should be assigned to tetrahedrally coordinated oligomeric $\mathrm{V}^{5+}$ species [20]. The third absorption band at $384 \mathrm{~nm}$ is related to pentagonal or pseudo-octahedral coordinated vanadium species interacting with moisture [21-23]. Moreover, a band at $446 \mathrm{~nm}$ was also observed, which should be connected with the presence of bulk vanadium(V) oxide species. Indeed, the results obtained for $\mathrm{V}_{\mathrm{M}}$ /SBA-15 are in-line with XRD diffractograms showing very low intensity peaks related to $\mathrm{V}_{2} \mathrm{O}_{5}$ crystalline phase. For all samples, after dehydration at $523 \mathrm{~K}$, the bands related to the hydrated species were very weak. The band at $244 \mathrm{~nm}$ dominated in the spectra, indicating a good dispersion of vanadium species and a relatively low concentration of vanadium oligomeric species. The kind of vanadium salt applied for modification of the SBA-15 material did not seem to influence the coordination of vanadium species, because very similar spectra were obtained for $\mathrm{V}_{\mathrm{M}}$ /SBA-15 and $\mathrm{V}_{\mathrm{S}} / \mathrm{SBA}-15$ samples. However, the treatment of vanadium-containing materials by TPS influenced the coordination of vanadium species, as evidenced in Figure S1. For the dehydrated samples, the dominant band appeared at ca. $250 \mathrm{~nm}$, whereas the intensity of the band at ca. $380 \mathrm{~nm}$ related to pentagonal or pseudo-octahedral vanadium species interacting with moisture decreased.

The state of vanadium species was also investigated using the ESR technique. The ESR spectra of all samples are presented in Figure S2, and the calculated parameters are listed in Table S1. All catalysts showed a characteristic ESR signal from $\mathrm{V}^{4+}(3 \mathrm{~d} 1)$ ion with typical hyperfine splitting (hfs) multiplets due to the interaction of an unpaired electron 
with nuclear spin $\mathrm{I}=7 / 2^{51} \mathrm{~V}$. The well-resolved hyperfine signals and values of $\mathrm{g}$ and $\mathrm{hfs}$ tensor parameters indicated well-dispersed $(\mathrm{VO})^{2+}$ species in square pyramidal or distorted octahedral coordination [24-27]. Moreover, all the identified isolated vanadyl species were also characterized by $\mathrm{g}_{\text {iso }}$ and $\mathrm{A}_{\text {iso }}$ parameters. The correlation diagram ( $\mathrm{g}_{\text {iso }}$ and $\mathrm{A}_{\text {iso }}$ ) produced according to the procedure proposed by Davidson and Che indicates the presence of 5-coordinated and 6-coordinated vanadyl species. The ability of a fraction of these species to adsorb water suggests the assignment to a 5-coordinated vanadyl group with a distorted octahedral structure and one coordination vacancy in the equatorial plane [28]. It is worth noting that for all catalysts, a very weak broad ESR signal from vanadium in the form of all kinds of clusters or agglomerations was observed. This suggests very weak spin-spin interactions between the $\mathrm{VO}^{2+}$ ions, which must be well dispersed.
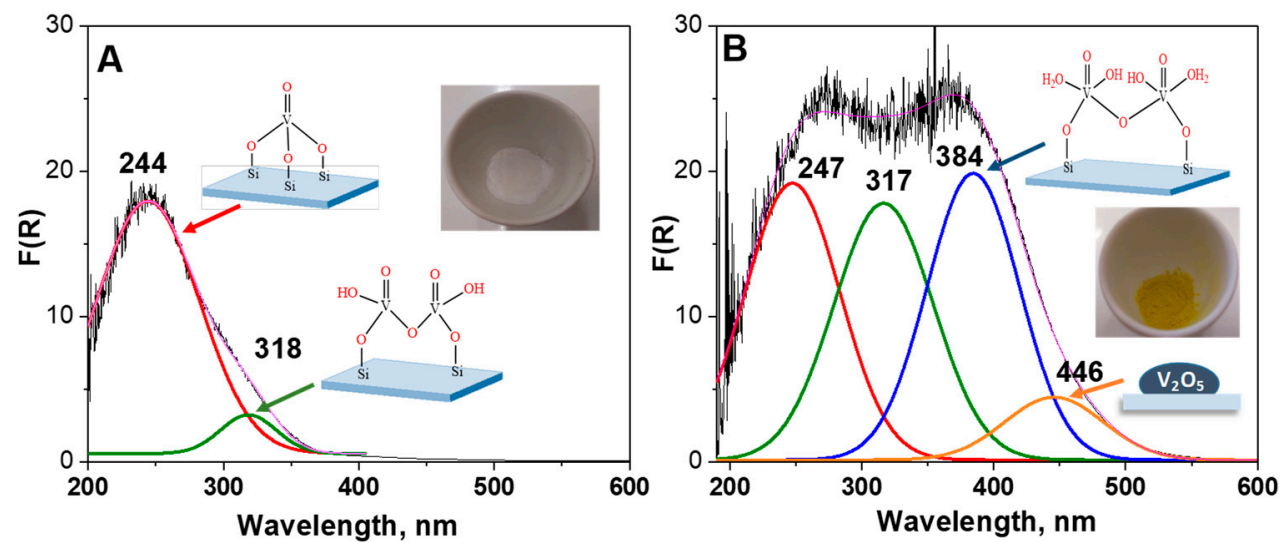

Figure 3. UV-Vis spectra of $\mathrm{V}_{\mathrm{M}}$ /SBA-15 sample: (A) dehydrated sample; (B) hydrated sample.

Figure 4 presents the ESR spectra of $\mathrm{V}_{\mathrm{M}} / \mathrm{SBA}-15$ and TPS/ $\mathrm{V}_{\mathrm{M}} / \mathrm{SBA}-15$. The ESR signal from $\mathrm{V}^{4+}$ in $\mathrm{V}_{\mathrm{M}} / \mathrm{SBA}-15$ material, after the treatment with TPS, became twice as small as the original one, which confirms the oxidation of vanadium by TPS species.

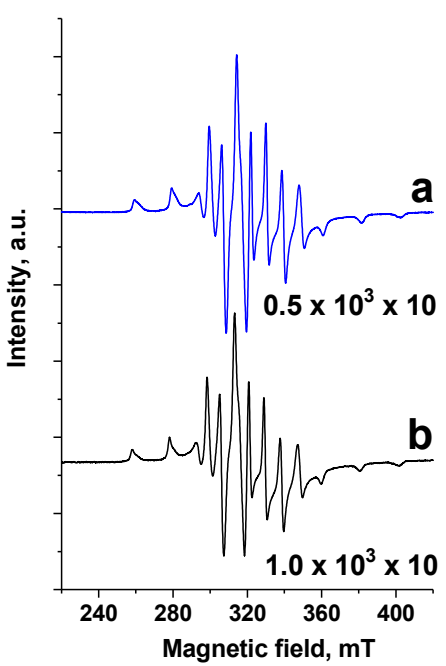

Figure 4. ESR spectra of (a) $V_{M} / S B A-15$ and (b) TPS/V $V_{M} / S B A-15$.

For further characterization of vanadium species, XPS analyses were performed. This method, as well as the elemental analysis, was used to exclude the presence of TPS species in the samples after interaction with vanadium species. For both TPS $/ \mathrm{V}_{\mathrm{M}} / \mathrm{SBA}-15$ and TPS/VS/SBA-15 samples, no bands related to the presence of sulfur were identified. The data from elemental analysis also indicated the lack of sulfur in the final material. Thus, one can conclude that there were no TPS species remaining in the samples after the interaction of vanadium-containing materials with organosilane. 
The XP spectra of vanadium-containing samples are presented in Figure 5. Up to three $\mathrm{V} 2 \mathrm{p}_{3 / 2}$ bands for different vanadium oxidation states can be observed in the spectra for different samples. The first band in the range of $517.5-518 \mathrm{eV}$ is related to $\mathrm{V}^{5+}$ [29-31] and was observed for the $\mathrm{V}_{\mathrm{S}} / \mathrm{SBA}-15$ sample before the interaction with TPS. This band was not observed for $\mathrm{V}_{\mathrm{M}}$ /SBA-15 material; however, it appeared after the treatment with TPS. This indicates the oxidation of vanadium species by sulfonic groups of TPS species. The second band at 516.5-516.6 eV, related to $\mathrm{V}^{4+}$, [29-31] was observed for all vanadium-containing samples, and it dominated for the materials before treatment with organosilane species. The intensity of this band in the XP spectra decreased after the interaction with TPS and became less pronounced than the band related to $\mathrm{V}^{5+}$. The last band at $515 \mathrm{eV}$ was observed only for $\mathrm{V}_{\mathrm{M}}$ /SBA-15 and according to the literature, it can be assigned to $\mathrm{V}^{3+}[29,30]$. This band was not intense and completely disappeared after interaction with TPS species.
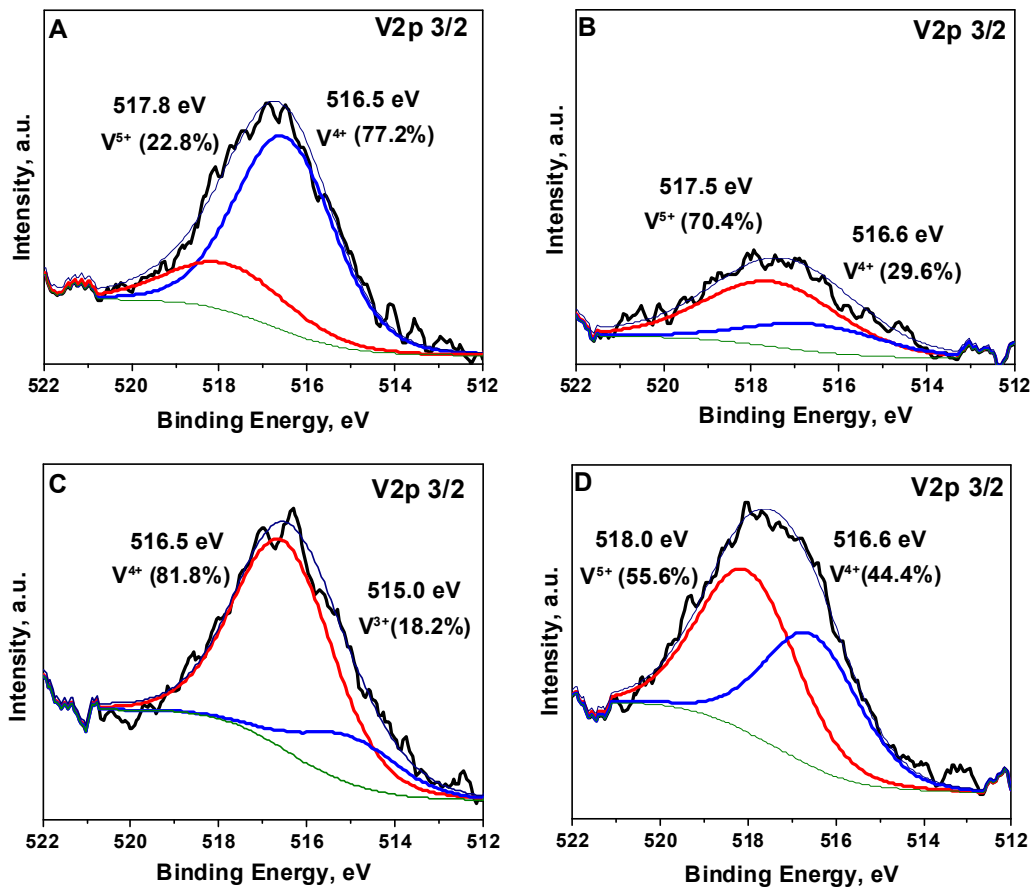

Figure 5. XP spectra of materials obtained in the $\mathrm{V} 2 \mathrm{p}$ region. (A) $\mathrm{V}_{\mathrm{S}} / \mathrm{SBA}-15$, (B) TPS/ $\mathrm{V}_{\mathrm{S}} / \mathrm{SBA}-15$, (C) $\mathrm{V}_{\mathrm{M}} / \mathrm{SBA}-15$, (D) $\mathrm{TPS} / \mathrm{V}_{\mathrm{M}} / \mathrm{SBA}-15$

Figure 5 also summarizes the fractions of each oxidation form of vanadium in the samples. The contribution of $\mathrm{V}^{5+}$ reached 70 and $56 \%$ for TPS $/ \mathrm{V}_{\mathrm{S}} / \mathrm{SBA}-15$ and TPS $/ \mathrm{V}_{\mathrm{M}} / \mathrm{SBA}-15$, respectively, whereas before the interaction with TPS species, the concentration of $\mathrm{V}^{5+}$ was 23 and $0 \%$, respectively. Thus, it was clearly seen that TPS oxidized vanadium species; however, after the impregnation-like procedure, TPS species did not remain on the material surface and did not contaminate the samples.

For determination of the type as well as the number of acid centers, FTIR spectroscopy combined with the adsorption of pyridine was applied. The interaction of pyridine with Lewis acid sites (LAS) resulted in the appearance of bands at ca. 1450 and $1610 \mathrm{~cm}^{-1}$ coming from the symmetric and antisymmetric stretching vibrations in pyridine coordinatively bonded to LAS, respectively [32]. The number of these sites can be estimated from the band intensity using the corresponding molar coefficient $\left(\varepsilon_{1450}=1.5 \mu \mathrm{mol}^{-1} \mathrm{~cm} \mathrm{[32]).}\right.$ When pyridine interacted with Brønsted acid sites (BAS), the characteristic band at ca. $1550 \mathrm{~cm}^{-1}$ from the symmetric vibrations of pyridinium cations-formed by the protonation of pyridine on BAS-appeared in the spectra $\left(\varepsilon_{1550}=1.8 \mu \mathrm{mol}^{-1} \mathrm{~cm}\right.$ [32]), which was accompanied by the bands assigned to the antisymmetric stretching vibrations in the $1620-1640 \mathrm{~cm}^{-1}$ range. Mesoporous silica of SBA-15 type did not exhibit acidity. Only some silanol groups can interact with pyridine, which can lead to the hydrogen bonding 
on the silica surface. This type of interaction is usually not strong and was manifested by the infrared band at ca. $1595 \mathrm{~cm}^{-1}$.

The FTIR spectra recorded after the adsorption of pyridine at $423 \mathrm{~K}$ and outgassing at the same temperature for $0.5 \mathrm{~h}$ are presented in Figure 6, while the calculated numbers of acid sites are shown in Table 2. Moreover, Figure S3 shows the spectrum of pyridine adsorbed on TPS/SBA-15, i.e., the material obtained via the interaction of TPS with SBA-15. Only two weak bands at 1596 and $1445 \mathrm{~cm}^{-1}$ were observed, indicating the interaction of pyridine with silanols by hydrogen bonding. For both samples modified with vanadium, i.e., $\mathrm{V}_{\mathrm{M}} / \mathrm{SBA}-15$ and $\mathrm{V}_{\mathrm{S}} / \mathrm{SBA}-15$, the band at $1450 \mathrm{~cm}^{-1}$ was observed, testifying to the presence of LAS. This band was more intense for $V_{M} / S B A-15$, which is in-line with the higher amount of vanadium in this sample. It can be observed that the intensity of the $1450 \mathrm{~cm}^{-1}$ band was much lower for TPS/ $\mathrm{V}_{\mathrm{M}} / \mathrm{SBA}-15$, and this band was not visible for TPS $/ V_{S} / S B A-15$. For the latter sample, this band was only observed after pyridine adsorption prior to evacuation (spectra not shown). This confirms again that during the interaction with TPS species, a part of vanadium species was removed from the sample. Moreover, it suggests that the strength of LAS is not high. This was also confirmed by the number of pyridine molecules interacting with LAS after outgassing at $473 \mathrm{~K}$ for $0.5 \mathrm{~h}$ (Table 2), which was more than twice as low.

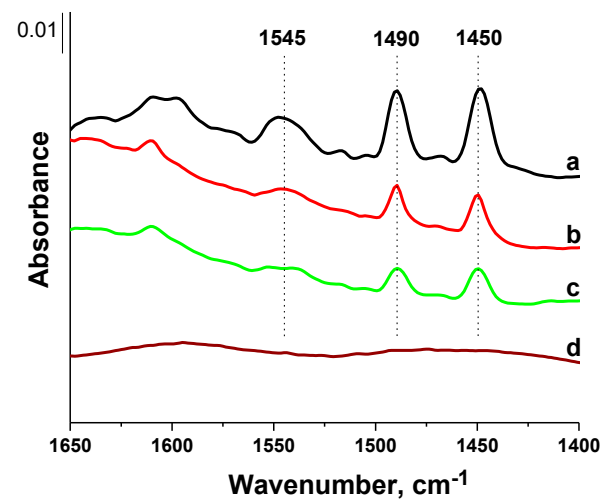

Figure 6. FTIR spectra recorded at room temperature after adsorption of pyridine at $423 \mathrm{~K}$ followed by desorption at $423 \mathrm{~K}$ for $0.5 \mathrm{~h}$ : (a) $\mathrm{V}_{\mathrm{M}} / \mathrm{SBA}-15$; (b) TPS/V $\mathrm{M} / \mathrm{SBA}-15$; (c) $\mathrm{V}_{\mathrm{S}} / \mathrm{SBA}-15$; (d) $\mathrm{TPS} / \mathrm{V}_{\mathrm{S}} / \mathrm{SBA}-15$.

Table 2. Number of Lewis (LAS) and Brønsted(BAS) acidic centers determined from the amount of pyridine remaining adsorbed after outgassing the samples at 423 and $473 \mathrm{~K}$.

\begin{tabular}{|c|c|c|c|c|}
\hline Catalyst & $\begin{array}{c}\text { LAS } \\
423 \mathrm{~K} \\
\left(\mu \mathrm{mol} \mathrm{g}^{-1}\right)\end{array}$ & $\begin{array}{c}\text { BAS } \\
423 \mathrm{~K} \\
\left(\mu \mathrm{mol} \mathrm{g}{ }^{-1}\right)\end{array}$ & $\begin{array}{c}\text { LAS } \\
473 \mathrm{~K} \\
\left(\mu \mathrm{mol} \mathrm{g}{ }^{-1}\right)\end{array}$ & $\begin{array}{c}\text { BAS } \\
473 \mathrm{~K} \\
\left(\mu \mathrm{mol} \mathrm{g}^{-1}\right)\end{array}$ \\
\hline $\mathrm{V}_{\mathrm{M}} / \mathrm{SBA}-15$ & 13.1 & 10.5 & 6.2 & 4.0 \\
\hline $\mathrm{TPS} / \mathrm{V}_{\mathrm{M}} / \mathrm{SBA}-15$ & 6.4 & 3.9 & 2.5 & 0.8 \\
\hline $\mathrm{V}_{\mathrm{S}} / \mathrm{SBA}-15$ & 5.6 & 2.1 & 0 & 0 \\
\hline TPS/V $/ \mathrm{SBA}-15$ & $5.3^{1}$ & 0 & 0 & 0 \\
\hline
\end{tabular}

${ }^{1}$ Value after short outgassing.

The adsorption of pyridine also resulted in the formation of pyridinium cation, which took place with the participation of BAS. This was much more pronounced for the $\mathrm{V}_{\mathrm{M}}$ /SBA-15 sample. The possible formation of BAS on vanadium-modified materials has been described in the literature [32]. The formation of BAS was related to the acidic proton in the $\mathrm{OH}$ group of the framework hydroxylated $(\mathrm{SiO})_{2}(\mathrm{HO}) \mathrm{V}=\mathrm{O}$ species. However, BAS species present on the vanadium-modified samples did not seem to be strong. The intensity of the band related to the interaction of the pyridinium ion with BAS significantly decreased for $\mathrm{V}_{\mathrm{M}}$ /SBA-15, and this band completely disappeared for $\mathrm{V}_{\mathrm{S}}$ /SBA-15. However, 
the decrease in the acidity of the samples treated with TPS should be related to a slightly lower concentration of vanadium species.

\section{Materials and Methods}

\subsection{Materials}

All chemicals and materials used were purchased from commercially available sources and used without further purification. Tetraethyl orthosilicate (TEOS) (>99\%), Pluronic P123, ammonium metavanadate $(99 \%)$ and vanadium(IV) oxide sulfate hydrate $(97 \%)$ were purchased from Sigma-Aldrich (St. Louis, MO, USA). $\mathrm{HCl}(35 \%)$ was procured from Stanlab (Lublin, Poland). 3-(trihydroxysiyl)-1-propanesufonic acid (30-35\% in water) was purchased from Gelest (Morrisville, PA, USA).

\subsection{Synthesis of $S B A-15$}

Mesoporous silica of SBA-15 type was obtained via hydrothermal synthesis. At first, a mixture of Pluronic P123 (Poly(ethylene glycol)-block-poly(propylene glycol)-blockpoly(ethylene glycol) (4g), $\mathrm{HCl}(8.76 \mathrm{~g}$ converted to $\mathrm{HCl})$ and water (141.24 g) was prepared. To this mixture, TEOS $(8.527 \mathrm{~g}$ ) was added dropwise at $313 \mathrm{~K}$ upon stirring. Finally, the mixture was stirred at $313 \mathrm{~K}$ for $20 \mathrm{~h}$ and then heated at $373 \mathrm{~K}$ under static conditions for next $24 \mathrm{~h}$. After synthesis, the product was washed with water and dried at room temperature. The template was removed by calcination at $823 \mathrm{~K}$ for $6 \mathrm{~h}$ (temperature ramp $5 \mathrm{~K} \mathrm{~min}^{-1}$ ).

\subsection{Incorporation of Vanadium}

Vanadium was introduced via incipient wetness impregnation. Prior to the modification, the SBA-15 material was outgassed in an evaporator flask for $1 \mathrm{~h}$ at $353 \mathrm{~K}$. Then, the support was filled with aqueous solution of ammonium metavanadate or vanadium(IV) oxide sulfate used in the amount that ensured that only the pores of SBA-15 would be filled. The amount of vanadium in the solution was sufficient to obtain $2 \% \mathrm{wt}$. of this metal in the final product. The mixture was rotated and heated in an evaporator flask at $353 \mathrm{~K}$ for $45 \mathrm{~min}$. The powder obtained was dried at $383 \mathrm{~K}$ for $18 \mathrm{~h}$ and calcined at $773 \mathrm{~K}$ for $6 \mathrm{~h}$ in air in static conditions (heating rate $5 \mathrm{~K} \mathrm{~min}^{-1}$ ).

\subsection{Treatment of Vanadium Species with TPS}

Vanadium-containing samples $(1 \mathrm{~g})$ were placed into a round bottom flask and treated with the water solution of TPS (molar ratio of $\mathrm{Si} / \mathrm{TPS}=10$ ) by rotating and heating in an evaporator flask at $353 \mathrm{~K}$ for $45 \mathrm{~min}$. Next, the sample was dried at $383 \mathrm{~K}$ for $18 \mathrm{~h}$.

\subsection{Characterization Techniques}

X-ray diffraction measurements were performed using a Bruker AXS D8 Advance diffractometer (Bruker, Karlsruhe, Germany) with $\mathrm{Cu} \mathrm{K} \alpha$ radiation $(\alpha=0.154 \mathrm{~nm}$ ) and at a step of $0.05^{\circ} \mathrm{s}^{-1}$.

$\mathrm{N}_{2}$ adsorption/desorption measurements were performed using the Micromeritics ASAP 2020 (Norcross, GA, USA). Prior to the $\mathrm{N}_{2}$ adsorption, the sample was outgassed at $373 \mathrm{~K}$ under vacuum $(<1.3 \mathrm{~Pa})$ for $20 \mathrm{~h}$. The surface area was calculated using the BET method with 6points of freedom, the correlation coefficient was at least 0.99997 and measurement error was less than $2 \mathrm{~m}^{2} \mathrm{~g}^{-1}$. Pore volume and diameter were determined by the DFT method.

Elemental analyses of vanadium-containing samples were carried out with an Elemental Analyser Vario EL III (Elementar Analysensysteme GmbH, Hanau, Germany).

Inductively coupled plasma optical emission spectrometry was performed using the ICP-OES 9820 Shimadzu, Kyoto, Japan.

XPS analyses were performed using an ultrahigh vacuum photoelectron spectrometer based on the Phoibos 150 NAP analyzer (Specs, Berlin, Germany). The operating pressure 
in the chamber was close to $5 \times 10^{-9} \mathrm{mbar}$. The materials examined were irradiated with a monochromatic $\mathrm{Al} \mathrm{K} \alpha$ radiation $(1486.6 \mathrm{eV})$.

UV-Vis spectra were recorded using a Varian-Cary 300 Scan UV-Visible Spectrophotometer (Candela, Warszawa, Poland). Powdered samples as obtained and, after dehydration at $523 \mathrm{~K}$, were placed into the cell equipped with a quartz window. The spectra were recorded in the range from 800 to $190 \mathrm{~nm}$. Spectralon was used as a reference material.

FTIR spectra combined with pyridine adsorption were recorded at $298 \mathrm{~K}\left(4000-400 \mathrm{~cm}^{-1}\right)$ with a Bruker Invenio S spectrometer (Bruker, Karlsruhe, Germany). Samples were pressed into thin wafers of ca. $10 \mathrm{mg} \mathrm{cm}^{-2}$ and placed inside the IR cell. Prior to the pyridine adsorption, the catalyst was outgassed at $573 \mathrm{~K}$ for $4 \mathrm{~h}$. Then, pyridine was adsorbed at $423 \mathrm{~K}$, followed by a short outgassing for $10 \mathrm{~min}$, and the spectrum was registered. The spectra were also registered after the outgassing of the catalyst at 423 and $473 \mathrm{~K}$ for $30 \mathrm{~min}$. The spectrum of the IR cell alone was subtracted from all recorded spectra. Lewis and Brønsted acid sites were calculated using the molar coefficient $\varepsilon_{1450}=1.5 \mu \mathrm{mol}^{-1} \mathrm{~cm}$ and $\varepsilon_{1550}=1.8 \mu \mathrm{mol}^{-1} \mathrm{~cm}$, respectively.

ESR measurements were conducted after the evacuation of the catalysts at various temperatures (RT to $473 \mathrm{~K}$ ). ESR spectra were recorded at $77 \mathrm{~K}$ on a RADIOPAN SE/X 2457 spectrometer (Radiopan, Poznań, Poland). A cavity operating at a frequency of $8.9 \mathrm{GHz}$ (X-band) was used.

\section{Conclusions}

In this work, the treatment of vanadium species loaded on mesoporous SBA-15 silica with 3-(trihydroxysilyl)-1-propanesulfonic acid (TPS) was investigated. The applied methodology allowed us to obtain a final material which did not contain TPS species, as evidenced by elemental analysis and XPS measurements. Nevertheless, the oxidation state and coordination of vanadium species changed after the TPS treatment. This resulted in the oxidation of $\mathrm{V}^{4+}$ to $\mathrm{V}^{5+}$ and a decrease in the amount of penta-coordinated vanadium species. This finding should be taken into account if one considers the application of TPS species instead of the commonly used (3-mercaptopropyl)trimethoxysilane (MPTMS) for the design of bifunctional catalysts with redox (vanadium) and acidic (sulfonic species) sites. These kinds of materials have already been synthesized and will be presented in a separate paper.

Supplementary Materials: The following are available online at https:/ /www.mdpi.com/2073-4 344/11/3/397/s1, Figure S1: UV-Vis spectra of hydrated and dehydrated samples; Figure S2: ESR spectra of vanadium-containing catalysts (fresh samples) recorded at $77 \mathrm{~K}$; Figure S3: FTIR spectra recorded at room temperature after adsorption of pyridine at $423 \mathrm{~K}$ followed by desorption at $423 \mathrm{~K}$ for $10 \mathrm{~min}$ on TPS/SBA-15; Table S1: Parameters of ESR spectra recorded at $77 \mathrm{~K}$ for the different catalysts.

Author Contributions: Conceptualization, M.Z. and M.T.; methodology, A.N. and M.T.; investigation, A.N., P.D., and M.T.; writing—original draft preparation, M.T.; writing—review and editing, A.N., M.Z., and M.T.; visualization, A.N., P.D., and M.T.; supervision, M.Z. and M.T.; project administration, M.Z. and M.T.; funding acquisition, M.Z. All authors have read and agreed to the published version of the manuscript.

Funding: This research was funded by National Science Centre in Poland, grant number 2018/29/B/ST5/00137.

Acknowledgments: National Science Center in Poland (project no. 2018/29/B/ST5/00137) is acknowledged for financial support.

Conflicts of Interest: The authors declare no conflict of interest.

\section{References}

1. Solsona, B.; Blasco, T.; Lopez Nieto, J.M.; Pena, M.L.; Rey, F.; Vidal-Moya, A. Vanadium oxide supported on mesoporous MCM-41 as selective catalysts in the oxidative dehydrogenation of alkanes. J. Catal. 2001, 203, 443-452. [CrossRef] 
2. Fukudome, K.; Ikenaga, N.-O.; Miyake, T.; Suzuki, T. Oxidative dehydrogenation of alkanes over vanadium oxide prepared with $\mathrm{V}(\mathrm{t}-\mathrm{BuO})_{3} \mathrm{O}$ and $\mathrm{Si}(\mathrm{OEt})_{4}$ in the presence of polyethyleneglycol. Catal. Today 2013, 203, 10-16. [CrossRef]

3. Trejda, M.; Millot, Y.; Chalupka, K.; Dzwigaj, S. Preparation of two series of VxSiBeta zeolite catalysts with V centres in framework and extra-framework positions and their application in selective oxidation of methanol. Appl. Catal. A Gen. 2019, 579, 1-8. [CrossRef]

4. Yalcin, O.; Molinari Erwin, J.E.; Onal, I.; Wachs, I.E. Role of Local Structure on Catalytic Reactivity: Comparison of Methanol Oxidation by Aqueous Bioinorganic Enzyme Mimic (Vanadium Haloperoxidase) and Vanadia-Based Heterogeneous Catalyst (Supported $\mathrm{VO}_{4} / \mathrm{SiO}_{2}$ ). ACS Catal. 2020, 10, 1566-1574. [CrossRef]

5. Vieira, L. Possato, L.; Chaves T.F.; Lee, J.J.; Sulmonetti, T.P.; Jones, Ch.W.; Martins, L. Insights into Redox Dynamics of Vanadium Species Impregnated in Layered Siliceous Zeolitic Structures during Methanol Oxidation Reactions. ChemCatChem 2020, 12, 141-151. [CrossRef]

6. Folco, F.; Valasquez Ochoa, J.; Cavani, F.; Ott, L.; Janssen, M. Ethanol gas-phase ammoxidation to acetonitrile: The reactivity of supported vanadium oxide catalysts. Catal. Sci. Tech. 2017, 7, 200-212. [CrossRef]

7. Goto, Y.; Shimizu, K.; Kon, K.; Toyao, T.; Murayama, T.; Ueda, W. $\mathrm{NH}_{3}$-efficient ammoxidation of toluene by hydrothermally synthesized layered tungsten-vanadium complex metal oxides. J. Catal. 2016, 344, 346-353. [CrossRef]

8. Piumetti, M.; Bonelli, B.; Massiani, P.; Dzwigaj, S.; Rossetti, I.; Casale, S.; Gaberova, L.; Armandi, M.; Garrone, E. Effect of vanadium dispersion and support properties on the catalytic activity of V-SBA-15 and V-MCF mesoporous materials prepared by direct synthesis. Catal. Today 2011, 176, 458-464. [CrossRef]

9. Santhanaraj, D.; Suresh, C.; Selvamani, A.; Shanthi, K. A comparison study between V-SBA-15 and V-KIT-6 catalysts for selective oxidation of diphenylmethane. New J. Chem. 2019, 43, 11554-11563. [CrossRef]

10. Dos Santos, M.B.; Andrade, H.M.C.; Mascarenhas, A.J.S. Oxidative dehydration of glycerol over alternative H,Fe-MCM-22 catalysts: Sustainable production of acrylic acid. Microporous Mesoporous Mater. 2019, 278, 366-377. [CrossRef]

11. Wu, S.T.; She, Q.M.; Tesser, R.; Di Serio, M.; Zhou, C.H. Catalytic glycerol dehydration-oxidation to acrylic acid. Catal. Rev. 2020, 62, 481-523. [CrossRef]

12. Possato, L.G.; Casinelli, W.H.; Garetto, T.; Pulcinelli, S.H.; Santilli, C.V.; Martins, L. One-step glycerol oxidehydration to acrylic acid on multifunctional zeolite catalysts. Appl. Catal. A Gen. 2015, 492, 243-251. [CrossRef]

13. Trejda, M.; Stawicka, K.; Dubinska, A.; Ziolek, M. Development of niobium containing acidic catalysts for glycerol esterification. Catal. Today 2012, 187, 129-134. [CrossRef]

14. Trejda, M.; Stawicka, K.; Ziolek, M. The role of Nb in the formation of sulphonic species in SBA-15 and MCF functionalized with MPTMS. Catal. Today 2012, 192, 130-135. [CrossRef]

15. Trejda, M.; Jądrzak, A.; Nurwita, A.; Kryszak, D. An efficient synthesis of acidic mesoporous materials. Catal. Today 2020, 354, 61-66. [CrossRef]

16. Thommes, M.; Kaneko, K.; Neimark, A.V.; Olivier, J.P.; Rodriguez-Reinoso, F.; Rouquerol, J.; Sing, K.S.W. Physisorption of gases, with special reference to the evaluation of surface area and pore size distribution (IUPAC Technical Report). Pure Appl. Chem. 2015, 87, 1051-1069. [CrossRef]

17. Gao, F.; Zhang, Y.; Wan, H.; Kong, Y.; Wu, X.; Dong, L.; Li, B.; Chen, Y. The states of vanadium species in V-SBA-15 synthesizedunder different $\mathrm{pH}$ values. Microporous Mesoporous Mater. 2008, 110, 508-516. [CrossRef]

18. Dzwigaj, S.; Massiani, P.; Davidson, A.; Che, M. Role of silanol groups in the incorporation of V in $\beta$ zeolite. J. Mol. Catal. A Chem. 2000, 155, 169-182. [CrossRef]

19. Capek, L.; Bulanek, R.; Adam, J.; Smolakova, L.; Sheng-Yang, H. Cicmanec, P. Oxidative dehydrogenation of ethane over vanadium-based hexagonal mesoporous silica catalysts. Catal. Today 2009, 141, 282-287. [CrossRef]

20. Fornes, V.; Lopez, C.; Lopez, H.H.; Martinez, A. Catalytic performance of mesoporous VOx/SBA-15 catalysts for the partial oxidation of methane to formaldehyde. Appl. Catal. A Gen. 2003, 249, 345-354. [CrossRef]

21. Keller, D.E.; Visser, T.; Soulimani, F.; Koningsberger, D.C.; Weckhuysen, B.M. Hydration effects on the molecular structure of silica-supported vanadium oxide catalysts: A combined IR, Raman, UV-vis and EXAFS study. Vibr. Spectrosc. 2007, 43, 140-151. [CrossRef]

22. El-Malki, E.-M.; Massiani, P.; Che, M. Introduction of vanadium species in $\beta$ zeolite by solid-state reaction: Spectroscopic study of v speciation and molecular mechanism. Res. Chem. Intermed. 2007, 33, 749-772. [CrossRef]

23. Gontier, S.; Tuel, A. Characterization of vanadium-containing mesoporoussilicas. Microporous Mesoporous Mater. 1995, 5, $161-171$. [CrossRef]

24. Kornatowski, J.; Wichterlova, B.; Jirkovsky, J.; Löffler, E.; Pilz, W. Spectroscopic studies of vanadium-substituted zeolitic silicates of MFI topology. J. Chem. Soc., Faraday Trans. 1996, 92, 1067-1078. [CrossRef]

25. Lee, C.H.; Lin, T.-S.; Mou, C.-Y. (VO) ${ }^{2+}$ ions immobilized on functionalized surface of mesoporous silica and their activity toward the hydroxylation of benzene. J. Phys. Chem. B 2003, 107, 2543-2551. [CrossRef]

26. Wark, M.; Brückner, A.; Liese, T.; Grünert, W. Selective catalytic reduction of $\mathrm{NO}$ by $\mathrm{NH}_{3}$ over vanadium-containing zeolites. J. Catal. 1998, 175, 48-61. [CrossRef]

27. Berndt, H.; Martin, A.; Brückner, A.; Schreier, E.; Müller, D.; Kosslick, H.; Wolf, G.-U.; Lücke, B. Structure and catalytic properties of VOx/MCM materials for the partial oxidation of methane to formaldehyde. J. Catal. 2000, 191, 384-400. [CrossRef] 
28. Paganini, M.C.; Acqua, L.D.; Giamello, E.; Lietti, L.; Forzatti, P.; Busca, G. An EPR study of the surface chemistry of the $\mathrm{V}_{2} \mathrm{O}_{5}-\mathrm{WO}_{3} / \mathrm{TiO}_{2}$ catalyst: Redox behaviour and state of V(IV). J. Catal. 1997, 166, 195-205. [CrossRef]

29. Silversmit, G.; Depla, D.; Poelman, H.; Marin, G.B.; De Gryse, R. Determination of the V2p XPS binding energies for different vanadium oxidation states $\left(\mathrm{V}^{5+}\right.$ to $\left.\mathrm{V}^{0+}\right)$. J. Electron. Spectrosc. 2004, 135, 167-175. [CrossRef]

30. Hryha, E.; Rutqvist, E.; Hyborg, L. Stoichiometric vanadium oxides studied by XPS. Surf. Interface. Anal. 2012, 44, 1022-1025. [CrossRef]

31. Feng, X.; Sun, B.; Yao, Y.; Su, Q.; Ji, W.; Au, C.-T. Renewable production of acrylic acid and its derivative: New insights into the aldol condensation route over the vanadium phosphorus oxides. J. Catal. 2014, 314, 132-141. [CrossRef]

32. Khabtou, S.; Chevreau, T.; Lavalley, J.C. Quantitative infrared study of the distinct acidic hydroxyl groups contained in modified Y zeolites. Microporous Mesoporous Mater. 1994, 3, 133-148. [CrossRef] 